\title{
Article
}

\section{Incorporating communication research to develop an environmental history of the Pecos River of Texas}

\author{
Ric Jensen
}

Near the turn of the Century, a woman in her 90s from Dodge City, Kansas was riding her horse near the Pecos River and she described it as a sea of saltgrasses...You had to be very close to the river to see it because the grass was so high

You could drink the water out of the springs in this area.

I used to ride down to the Pecos River on horseback...There was a lot more water in it back then.

We grew cantaloupes... and people were amazed at how sweet they were... We stopped because the water [became] was too salty.

In 1903, fresh watercress and ferns were growing at Independence Springs [on the Lower Pecos River]... and there were pools of catfish and silver bass. Residents along Independence Creek sold minnows and other bait fish they took from the river.

We had a terrible flood in 1941 and 1942 which breached Zimmerman Dam. The river at some places was 10 miles wide. Floodwater covered the valley and the dam was washed out.

It seems there is always less water in the Pecos than we need... I think the water quality is worse nownot that the Pecos River was ever beautiful and clear.

When my grandfather got here 110 years ago, they had a lot of water problems then.

The prospect of fixing the saltcedar problem and making this area come back the way it was 100 years ago looks bleak for to me...I don't know if we can do that

--Quotes from long-time residents of the Pecos River of Texas

\section{Overview}

The idea of using communication research to develop natural resources histories has been documented in several studies, but I contend that these methods are largely underutilized. The point of this paper is to demonstrate how the use of one communication research method-lengthy personal face-to-face interviews analyzed with qualitative methods-can aid efforts to develop histories pertaining to the environment.

As an introduction, naturalistic inquiry is a qualitative research method that emphasizes the importance of studying an issue in its natural context using observation, case studies, open-ended interviews, and ethnographic methods. Insights gained through naturalistic studies are then confirmed through member checking, auditing by peers, triangulation, and other methods. Hoepfl (1997) suggests that naturalistic inquiry and related qualitative methods are especially useful when researchers seek illumination, insights, and greater understanding that can be extrapolated to similar situations. Hoepfl recommends that openended questions can be especially important qualitative tools when the goal is to gain more in-depth information and new perspectives about complex issues.

D'Andrea \& Daniels [1] provide an introduction to the naturalistic research methodology and state

\footnotetext{
Researchers who use naturalistic inquiry operate from the assumption that there are multiple realities that are mentally constructed by the research participants. When using a naturalistic inquiry approach to explore these multiple constructions of reality, researchers are encouraged to act as participant-observers who operate within the context in which the research is being conducted.
}

Sandelowski [13] describes naturalistic inquiry as follows: 


\begin{abstract}
Naturalistic inquiry is a generic orientation to inquiry that includes not only qualitative research but also behavioral research... Naturalistic inquiry implies only a commitment to studying something in its natural state. In any naturalistic study, there is no pre-selection of variables to study, no manipulation of variables, and no a priori commitment to any one theoretical view of a target phenomenon.
\end{abstract}

A few studies note how the analysis of communication can enhance environmental studies. For example, Lankard \& McLaughlin [7] used qualitative methods to develop a content analysis in order to assess the extent to which an environmental organization consistently communicated "green" messages in its marketing and public relations campaigns. Mascarenhas \& Scarce [9] described how the qualitative analysis of in-depth interviews revealed new insights into the attitudes of natural resources managers about forestry policies.

On a broader level, several researchers discuss how qualitative studies and naturalistic inquiry can be used to strengthen natural resources research. Knapp \& Poff [6] describe the use of naturalistic methods to learn about the perceptions of youth who participated in field trips to a forest. Fredrickson \& Anderson [2] discuss how on-site observations, reflexive journals, and in-depth interviews were used to examine the experiences of people who hiked through wilderness areas. Stirling [14] urged that it is essential to develop a full history of environmental sites and related issues by using naturalistic methods along with traditional technical studies.

The importance of incorporating communication research into natural resources studies was eloquently stated by Lincoln, Thorp \& Russon [8], page 267) when they said:

\begin{abstract}
We suggest not only that evaluators and researchers should cultivate their capacity to hear and tell stories, but also that agricultural programs and their long-term impacts could benefit from different kinds of evaluation efforts. From this perspective, the evaluation or research report is no longer an attempt to mirror reality, but rather is an evocative story that asks the reader to engage the story morally, emotionally, aesthetically, and intellectually, as well as from a social impact perspective.
\end{abstract}

\title{
Using communication research to develop a history of the pecos river of Texas
}

The Texas Water Resources Institute, based at Texas A\&M University in College Station, has recently carried out several watershed studies funded through the Clean Water Act. One of these grants funded The Pecos River Assessment Project-an effort to restore water quality and water supplies in this arid and desolate watershed. Originally, the purpose of the project was to utilize agronomic and engineering studies to clear saltcedar to increase the flow of water in the river and to identify the source of significant salt runoff from groundwater formations with the idea of diverting these contaminants before they enter the river.

When I was asked to assist the project, the first thing that struck me was that word restore. If the Pecos River were to be restored, saved or salvaged by our efforts, how would we know what goals should be set in such an effort? One answer quickly became apparent: In order to restore the Pecos, we would first have to know what the river was like, broadly speaking, before it was affected by human settlement.

Working on that premise, I began to search for and look at reports and articles about the Texas portion of the Pecos. Most of the information I found focused on the current state of the Pecos: the idea that the river had suffered because the state of New Mexico had withheld water deliveries and perhaps used too much water, the proliferation of saltcedar that consumes and wastes water that should flow downstream, and the extreme salinity that inhibits the growth of most crops the few remaining farmers choose to plant. In contrast, I initially found very few articles that discussed conditions in the Pecos when European settlers arrived in the 1800s, when the area was influenced by Spanish explorers, or when the region was populated by Native Americans.

At that point, I decided that the best, maybe the only, way to help restore the Pecos was to try to do what I could to document the original condition of the watershed.

In my doctoral work, I used naturalistic methods to learn how stakeholders viewed the importance of academic research compared to teaching and service [5]. Based on this experience, I wanted to see if I could employ my qualitative research skills to help develop an overarching history of the Pecos River of Texas. 
The idea was to gain a first-hand perspective about how these individual recalled the Pecos River watershed several generations ago. Through these interviews, I hoped to capture some of the "lost" history that had not found its way into academic papers, agency reports, or the mass media.

In this process, I first contacted Texas A\&M scientists working in the Pecos region to set up lengthy face-to-face interviews with long-time residents of the region. Thus purposive sampling was used to identify the first set of interviewees. Initially, I interviewed 10 long-time residents throughout a region that stretched from the Texas-New Mexico border to the mountains that separate Texas from Mexico.

During each open-ended unscripted interview, comments were recorded by hand in bound journals. Generally speaking, the interviews lasted between 60 and 90 minutes. Afterwards, the interviews were transcribed and sent back to the people I spoke with for member checking. In the course of conducting interviews, I prodded the people I spoke with to provide the names and contacts for others I should speak with using an informal version of a snowball technique. Once the interviews were conducted, data from the individual transcripts were chunked and naturalistic methods were used to identify patterns and themes (important or frequently-mentioned issues). Some of the themes that emerged from the data relate to efforts to dam the river, the development of agriculture, plans to bring settlers to the region to build cities, how the development of groundwater pumping affected irrigated farming, the types of crops that were grown, challenges posed by the harsh environment and scarce water resources that makes it difficult to survive in this area, and the salinity of the river.

Because so little was known about the early history of the Pecos River basin, I did not begin with any preconceived "a priori" conceptions about what topics would be addressed in developing the history of the region. In contrast, I relied on the information uncovered during interviews, content analysis of historic and contemporary documents, and other sources in a context of grounded theory. In basic terms, grounded theory forces the researcher to shape the direction a research project may take by the kinds of information at are revealed as the study unfolds (Pandit [10]. For example, Parker \& Roffey [11] describe how grounded theory can be used to generate theories that offer the prospect of reflecting the complexity and richness of individual and group behavior within complex organizations. Grounded theory about a specific topic evolves in an iterative manner as new information is analyzed and greater insights are revealed. In a grounded theory approach, the information gleaned from previous interviews and observations guides the types of questions that are asked and issues that are explored in subsequent data gathering.

Parry [12] describes grounded theory in the following way:

\begin{abstract}
Grounded theory is a research method in which theory emerges from, and is grounded in, the data... A grounded theory is inductively derived from the study of the phenomenon it represents...Grounded theory is discovered, developed and provisionally verified through systematic data collection and analysis of data pertaining to that phenomenon...(When using grounded theory) one does not begin with a theory, then prove it. Rather, one begins with an area of study and what is relevant to that area is allowed to emerge.
\end{abstract}

Throughout the process, significant efforts were made to triangulate the information provided by respondents by searching for such documents as agricultural censuses, agency reports, academic papers, and magazine and newspaper accounts. In several cases, the process of seeking information for triangulation led me to more people I needed to speak with (either in-person or over the phone) thus adding to the snowball effect.

Information gained from these interviews was incorporated into a technical report in two distinct ways. Most obviously, short summaries that gleaned the highlights of the people I spoke with were presented as an appendix to the technical report. In a more subtle way, information from the interviews formed the basis of much of the factual information presented in the body of the report. In other words, had I not spoken with a woman who spent much of her youth on the lower reach of the Pecos River I wouldn't have the idea to follow-up and search for more information about massive floods that afflicted the region or how the water quality and aquatic habitat improved as one went downstream. 


\section{Discussion}

By interviewing long-time residents of the Pecos region in-person, I gained a broader and richer perspective than could have been obtained if I only examined engineering studies and technical reports. From a natural resources point of view, these long-time residents told me about the extreme variations in flows of the river (from droughts to floods), the types of vegetation that existed before saltcedar spread throughout the area, the salty nature of the river as well as sites in the watershed that provided higher quality water, and the types of terrestrial and aquatic species that existed in this remote ecosystem. Perhaps more importantly, these individuals told me about how man's efforts to tame and manage the river had affected the lives of people who tried to eke out a living in this harsh environment. I heard heartfelt stories of attempts to bring agricultural irrigation to the Pecos and create a man-made oasis, to design and build cities based on the promise of new wealth brought by irrigated farming, and the brief rise and fall of towns and settlements that sprung out of nowhere and flourished for a brief time only to become transformed into uninhabited ghost towns. I had people tell me of work long-ago to build brush- and rock-dams to provide freshwater for irrigation, the devastating consequences for agriculture when those dams burst, and current plans to convince people of the need to rebuild those dams - some of the people were convinced the Pecos could be saved if only people understood the problems the watershed faces and how to solve them. I learned of the backroom political complexities and disagreements that one could only understand by learning the inside hidden history that went unpublished. Throughout this process, I could sense in the voices and facial expressions of those with whom I spoke their passion for recovering and reclaiming the Pecos River region and making it vibrant and prosperous, even after several previous attempts to reclaim this watershed had failed.

After interviewing this first set of 10 long-time residents, we have now identified at least 10 more people to interview using these methods. These interviews will take place this summer.

\section{Conclusion}

In most of the natural resources projects that I have been engaged with, the emphasis has largely been placed on the physical sciences. It's not that we don't talk with people and do our work in an impersonal vacuum but we don't usually lay forth a communication research agenda to get a more complete picture of natural histories. There isn't any malice or deliberate attempt to avoid using communication research in our scholarship; instead the fact is that most of our research grants are awarded to people in physical science disciplines.

That being said, I contend that incorporating communication research into ecosystem studies can significantly broaden the promise of what can be learned and can yield richer results. In this case, developing and implementing a communication research strategy allowed us to learn much more about the early conditions of the river than what has heretofore been published. It led us to explore issues we may have otherwise overlooked (i.e., efforts to build small dams to capture water for irrigation) and led us to additional people to meet and sources of information to explore. The communication research also enhanced the types of technical information in the final report as, through the process of triangulation, we obtained hard-to-find reports with detailed accounts of vegetation trends, hydrology, and geology. Perhaps most importantly, by meeting with and listening to long-time residents we got a much better look at the trials, sorrows, and dashed hopes people in this harsh and inhospitable environment endured and their still-dogged determination to improve water resources conditions in the area.

Coming full-circle, the question must again be asked- "What should the Pecos River be restored to?" I contend that by applying communication research methods we have developed a much broader tapestry of the condition of the Pecos River as it existed when European settlers first arrived. This history can guide today's scientists and watershed planners as they try to develop ways to restore the waters of the region and re-create conditions as they existed long ago. A technical report that presents how human activities have altered the Pecos Basin of Texas was published by the Institute in 2006 [4].

I urge that others studying natural resources issues also consider developing and implementing other types of communication research principles in order to create improved histories of the environment. If you are especially interested in seeking out long-term residents, I suggest that you ought to work with a sense or urgency. If you wait too long these aged individuals may pass away before you have time to speak with them thus missing a chance to capture a first-hand look at natural resources history that will otherwise be lost. 


\section{Refereces}

[1] M. D'Andrea and J. Daniels, Exploring the Psychology of White Racism through Naturalistic Inquiry, Journal of Counseling \& Development 77 (1999) 93.

[2] L. Fredrickson and D. Anderson, A Qualitative Exploration of the Wilderness Experience As A Source of Spiritual Inspiration, Environmental Psychology 19 (1999) 21.

[3] M. Hoepfl, Choosing Qualitative Research: A Primer for Technology Education Researchers, Journal of Technology Education 9 (1997) 47.

[4] R. Jensen, C. Hart, M. Mecke and W. Hatler, The Influence of Human Activities on the Waters of the Pecos Basin of Texas, TWRI technical report SR-2006-03 (2006).

[5] R. Jensen, Understanding How the Public Perceives the Importance of University Research In the United States, Science Communication 4 (2005) 1.

[6] D. Knapp and R. Poff, A Qualitative Analysis of the Immediate and Short-Term Impact of an Environmental Interpretive Program, Environmental Education Research 7 (2001) 55.

[7] A. Lankard and W. McLaughlin, Marketing an Environmental Issue: A Case Study of The Wilderness Society's Core Messages to Promote National Forest Conservation from 1964- to 2000, Society \& Natural Resources 16 (2003) 415.

[8] Y. Lincoln, L. Thorp and C. Russon, The Storied Nature of Agriculture and Evaluation: A Conversation, Agriculture and Human Values 20 (2003) 267.

[9] M. Mascarenhas and R. Scarce, 'The Intent Was Good': Legitimacy, Consensus-Based Decision Making, and the Case of Forest Planning in British Columbia, Canada, Society \& Natural Resources 17 (2004) 17.

[10] N. Pandit, The Creation of Theory: A Recent Application of the Grounded Theory Method, The Qualitative Report 2 (1996) 1.

[11] L. Parker and B. Roffey, Back to the Drawing Board: Revisiting Grounded Theory and the Everyday Accountant's and Manager's Reality, Accounting, Auditing \& Accountability Journal, 10 (1996) 212.

[12] K. Parry, Grounded Theory and Social Process: A New Direction for Leadership Research, Leadership Quarterly, 9 (1998) 85.

[13] M. Sandelowski, What Ever Happened to Qualitative Description?, Research in Nursing \& Health 23 (2000) 334.

[14] D. Stirling, Site Histories in Environmental Site Assessments: A New Opportunity for Public Historians, The Public Historian 12 (1990) 44.

\section{Notes}

The TWRI Pecos Basin Assessment Project was funded by The Texas State Soil and Water Conservation Board and the Texas Commission on Environmental Quality. As a result of this project, a watershed protection plan for the Pecos River of Texas was published in August 2007 by the Texas Water Resources Institute.

Leaders of the Pecos Basin project included Dr. Allan Jones and Dr. B.L. Harris of TWRI, Dr. Charles Hart of the Texas Agricultural Experiment Station and Texas Cooperative Extension, and Mr. Mike Mecke and Mr. Will Hatler of Texas Cooperative Extension. A technical report about the history of the Pecos Basin of Texas is available by contacting Jensen at rwjensen@ag.tamu.edu.

\section{Author}

Ric Jensen is an Assistant Research Scientist with the Texas Water Resources Institute at Texas A\&M University. The communications research presented in this paper is part of a larger study funded by the United States Environmental Protection Agency to develop a watershed protection plan for the Pecos River basin. For more than 20 years, Jensen has worked to apply communications research to increase public understanding of environmental issues. E-mail:rwjensen@ag.tamu.edu. 